\title{
Developing a Sustainable Business Excellence Model - Factors for Successful Self-Assessment and Implementation in the Middle East
}

\author{
Adil Ahmed El Tigani and William Keogh \\ Heriot-Watt University (UK)
}

Paul Gardiner

The British University in Dubai (UAE)

Rodney McAdam

University of Ulster, UK

\begin{abstract}
The paper investigates the development of an Excellence Model derived from the EFQM Excellence Model and implemented in the United Arab Emirates, Dubai Municipality. The model used is closely aligned with the original EFQM Excellence Model. A small number of changes were made to address local contextual and cultural issues. The paper also investigates the perceptions of users of the model after implementation in terms of the process of implementation and the benefits gained. Difficulties of implementation were identified and discussed, specially those related to large organisations. The results showed that a major factor for success is the strategic alignment of views towards the model in the organisation; the choice of technique used for selfassessment is also an important factor.
\end{abstract}

\section{Introduction}

Recently, there has been a growing interest in the practice of organisational self-assessment based on generic TQM frameworks, such as the Malcolm Baldrige award in the US and the EFQM Excellence Model (EM) in Europe. Interest in these models is growing around the world, either as initiatives in organisations or as national quality awards. The EM is adopted in a number of countries. The Dubai Government Excellence Program (DGEP) is based on the EM, with the same nine criteria and minor differences in the sub-criteria. The model is used in public sector organisations in Dubai and has produced significant benefits. This research investigates the implementation of the DGEP in the Dubai Municipality, a large government organisation in the United Arab Emirates. The research also investigates the factors that lead to successful implementation.

\section{Dubai Government Excellence Program}

On October 1997 The Government of Dubai developed the DGEP as the main framework for self-assessment and as a basis of awards for government organisations. The model was revised in 2003 and again in March 2007. The DGEP is based on the EM. The two models are identical in the nine criteria (see Figure 1), with very minor differences in the sub-criteria (see Table 1, minor differences shaded), namely, in the Leadership criteria the DGEP has added the subcriterion: Leaders develop an environment of innovation. Also in the People criteria an additional sub-criteria is: The organization is committed to nationalization (Emiratization) of jobs. This is a natural result due to the special nature of employment market in the UAE where expatriates 
represent approximately 85 per cent of the workforce (Fernandes and Awamleh, 2006). Figure 1 shows the nine criteria of the model. The DGEP recognises that the EFQM is the owner of the original model (DGEP, 2007), hence for the purpose of this research all literature related to the EFQM is assumed to be applicable to the DGEP.

\section{Fig. 1 (EFQM/DGEP Excellence Model)}

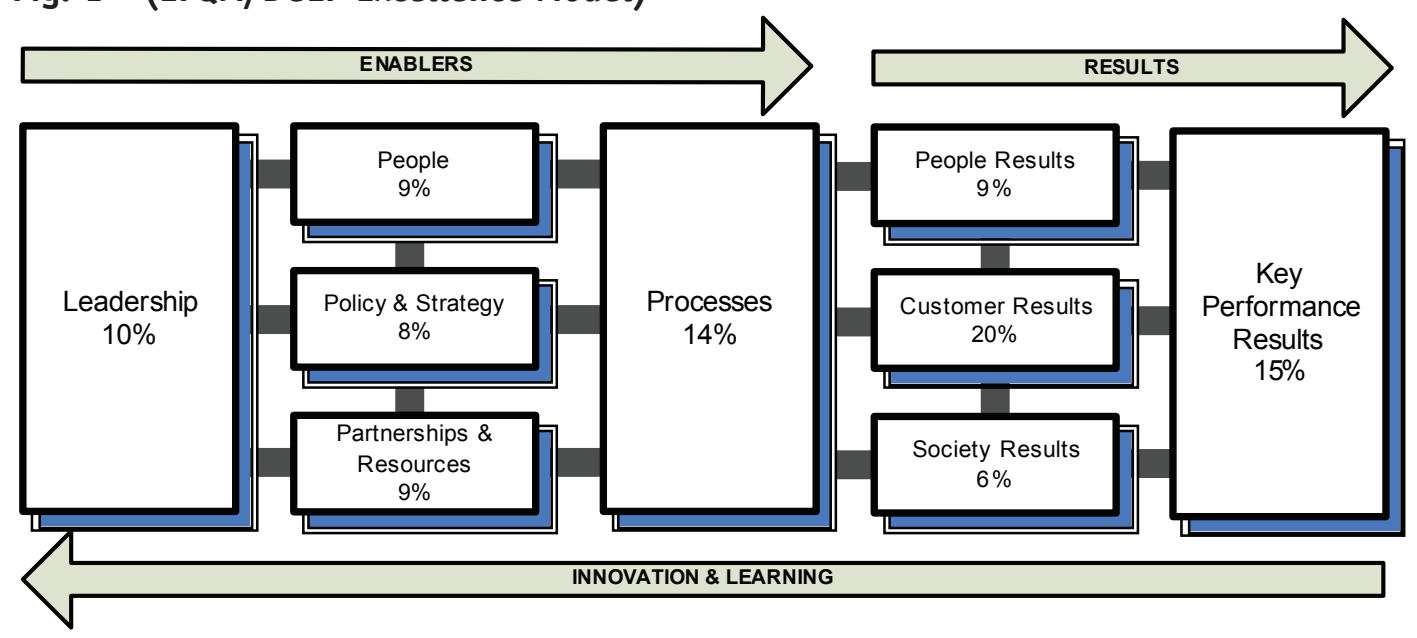

\section{Table 1 Comparison between the EFQM and the DGEP criteria}

\begin{tabular}{|c|c|c|c|}
\hline \# & CRITERIA & EFQM & DGEP \\
\hline 1 & LEADERSHIP & $\checkmark$ & $\checkmark$ \\
\hline 1.1 & $\begin{array}{l}\text { Leaders develop the mission, vision, values and ethics and are role models } \\
\text { of a culture of Excellence }\end{array}$ & $\checkmark$ & $\checkmark$ \\
\hline 1.2 & $\begin{array}{l}\text { Leaders are personally involved in ensuring the organisation's management } \\
\text { system is developed, implemented and continuously improved }\end{array}$ & $\checkmark$ & $\checkmark$ \\
\hline 1.3 & Leaders interact with customers, partners and representatives of society & $\checkmark$ & $\checkmark$ \\
\hline 1.4 & Leaders reinforce a culture of Excellence with the organisation's people & $\checkmark$ & $\checkmark$ \\
\hline 1.5 & Leaders develop an environment of innovation & & $\checkmark$ \\
\hline 1.6 & Leaders identify and champion organisational change & $\checkmark$ & $\checkmark$ \\
\hline 2 & POLICY AND STRATEGY & $\checkmark$ & $\checkmark$ \\
\hline 2.1 & $\begin{array}{l}\text { Policy and Strategy are based on the present and future needs and expecta- } \\
\text { tions of stakeholders }\end{array}$ & $\checkmark$ & $\checkmark$ \\
\hline 2.2 & $\begin{array}{l}\text { Policy and Strategy are based on information from performance measure- } \\
\text { ment, research, learning and external related activities }\end{array}$ & $\checkmark$ & $\checkmark$ \\
\hline 2.3 & Policy and Strategy are developed, reviewed and updated & $\checkmark$ & $\checkmark$ \\
\hline 2.4 & $\begin{array}{l}\text { Policy and Strategy are communicated and deployed through a framework } \\
\text { of key processes }\end{array}$ & $\checkmark$ & $\checkmark$ \\
\hline 3 & PEOPLE & $\checkmark$ & $\checkmark$ \\
\hline
\end{tabular}




\begin{tabular}{|c|c|c|c|}
\hline 3.1 & People resources are planned, managed and improved & $\checkmark$ & $\checkmark$ \\
\hline 3.2 & People's knowledge and competencies are identified, developed and sustained & $\checkmark$ & $\checkmark$ \\
\hline 3.3 & People are involved and empowered & $\checkmark$ & $\checkmark$ \\
\hline 3.4 & People and the organisation have a dialogue & $\checkmark$ & $\checkmark$ \\
\hline 3.5 & People are rewarded, recognised and cared for & $\checkmark$ & $\checkmark$ \\
\hline 3.6 & The organization is committed to nationalization (Emiratization) of jobs & & $\checkmark$ \\
\hline 4 & PARTNERSHIPS AND RESOURCES & $\checkmark$ & $\checkmark$ \\
\hline 4.1 & External partnerships are managed & $\checkmark$ & $\checkmark$ \\
\hline 4.2 & Finances are managed & $\checkmark$ & $\checkmark$ \\
\hline 4.3 & Buildings, equipment and materials are managed & $\checkmark$ & $\checkmark$ \\
\hline 4.4 & Technology is managed & $\checkmark$ & $\checkmark$ \\
\hline 4.5 & Information and knowledge are managed & $\checkmark$ & $\checkmark$ \\
\hline 5 & PROCESSES & $\checkmark$ & $\checkmark$ \\
\hline 5.1 & Processes are systematically designed and managed & $\checkmark$ & $\checkmark$ \\
\hline 5.2 & $\begin{array}{l}\text { Processes are improved, as needed, using innovation in order to fully satisfy } \\
\text { and generate increasing value for customers and other stakeholders }\end{array}$ & $\checkmark$ & $\checkmark$ \\
\hline 5.3 & $\begin{array}{l}\text { Products and Services are designed and developed based on customer needs } \\
\text { and expectations }\end{array}$ & $\checkmark$ & $\checkmark$ \\
\hline 5.4 & Products and Services are produced, delivered and serviced & $\checkmark$ & \\
\hline 5.5 & Customer relationships are managed and enhanced & $\checkmark$ & $\checkmark$ \\
\hline 6 & CUSTOMER RESULTS & $\checkmark$ & $\checkmark$ \\
\hline 6.1 & Perception Measures & $\checkmark$ & $\checkmark$ \\
\hline 6.2 & Performance Indicators & $\checkmark$ & $\checkmark$ \\
\hline 7 & PEOPLE RESULTS & $\checkmark$ & $\checkmark$ \\
\hline 7.1 & Perception Measures & $\checkmark$ & $\checkmark$ \\
\hline 7.2 & Performance Indicators & $\checkmark$ & $\checkmark$ \\
\hline 8 & SOCIETY RESULTS & $\checkmark$ & $\checkmark$ \\
\hline 8.1 & Perception Measures & $\checkmark$ & $\checkmark$ \\
\hline 8.2 & Performance Indicators & $\checkmark$ & $\checkmark$ \\
\hline 9 & KEY PERFORMANCE RESULTS & $\checkmark$ & $\checkmark$ \\
\hline 9.1 & Key Performance Outcomes & $\checkmark$ & $\checkmark$ \\
\hline 9.2 & Key Performance Indicators & $\checkmark$ & $\checkmark$ \\
\hline
\end{tabular}

(sources: EFQM, 2003 and DGEP, 2003) 
The DGEP offers seven awards in the category of Administrative Excellence which are offered every two years, and nine in the Employees Excellence Category offered annually.

\subsection{Self-assessment}

The approach to organisational self-assessment should consider the culture and the quality maturity of the organisation (Samuelsson and Nilsson, 2002). Dale (1996) argues that organisations need about three years of practice in TQM before they can benefit from the process of self-assessment. Van der Wiele et al. (1996) conducted research involving universities from six European countries, in which they list five important reasons for organizations to start the self-assessment process, which are: find opportunities for improvement; create a focus on the TQM model portrayed by the award criteria; direct the improvement process; provide new motivation for the improvement process; and manage the business. Organisations need to understand clearly why they want to conduct self-assessment in order to maximise benefits from the process. A big challenge also, is how to link the process of self assessment with the other activities of the organisation (EFQM, 2003), this is important to get the appropriate attention and commitment from the people of the organisations. Unsynchronised quality initiatives will lead to chaos, loss of strategic direction, and will lessen the interest, commitment and management credibility in the eyes of employees.

\section{Dubai Municipality Background}

Dubai Municipality is one of the largest government organisations in Dubai. It is considered to be the major driver of development in the UAE. The organisation structure (at time of research) consists of 31 business units and 24 departments organised around six major sectors. About 11,000 employees are employed by the municipality, including expatriates from different parts of the world mainly from Arab and Asian countries.

In every department there is a small quality unit (2-5 employees) which works in coordination with the central quality department in strategy and quality issues. The Dubai Municipality (DM) was the first winner of the award in 1998, followed by many other prestigious awards in different categories of the program. The DGEP conducts the award assessment for government organisations every two years and likewise the Municipality conducts self-assessment every two years, but alternatively with the award.

Figure 2 outlines the DM approach to Organisational Assessment. It consists of three processes. The input to the Plan for Assessment process is the results of the previous assessment, strategic plan, methodologies, KPIs, and stakeholders' satisfaction surveys. The input to second process, Conduct assessment and prepare reports, is the assessment plan while the output is the assessment reports of the different business units including the improvement plans. The assessment technique followed is the workshop technique. In this method the departments prepare for evidence as per the criteria of the model, this evidence is then presented to the assessors in a workshop that lasts for one day usually. The assessors use a technique known as RADAR logic to score the evidence for each criteria.

\section{Critical Success Factors (CSFs)}

From the literature review it was found that different authors have different views on the critical factors for successful implementation of TQM. Most of the literature reviewed were results of research 


\section{Fig. 2 DM organizational assessment management approach}

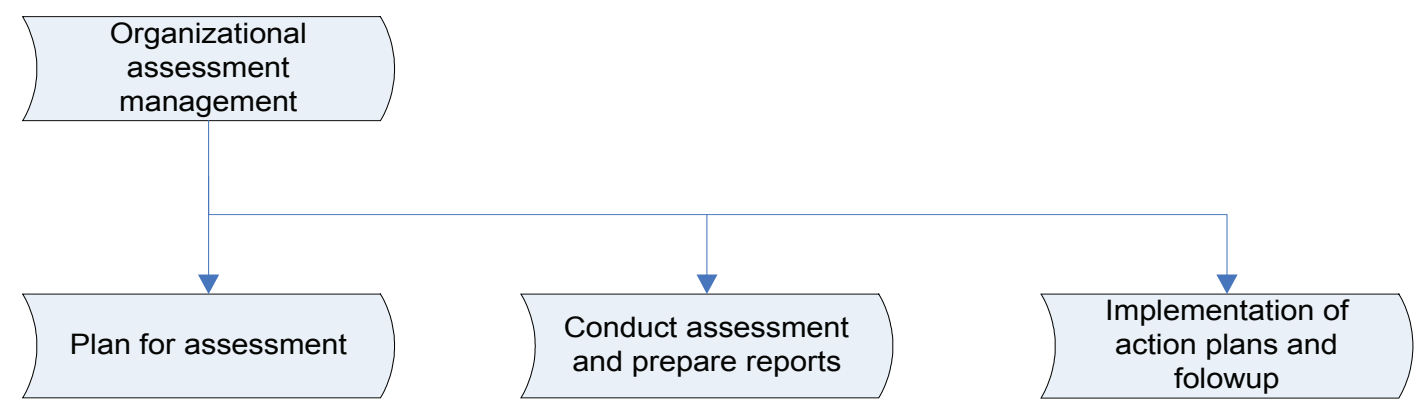

Source: DM process management system (ARIS)

in western countries; few articles are published about research carried out in other parts of the world, especially the Middle East, with the exception of Badri et al. (1995) and Al-Mary et al. (2007).

This research takes advantage of the intensive literature review done by Karuppusami and Gandhinthan (2006) about the critical success factors (CSFs) of TQM in the academic publications from 1989 to 2003. Their work reveals a number of empirical studies with the composition of fifty six CSFs. According to the frequency of appearance of each CSF in the literature Karuppusami and Gandhinthan used Pareto analysis to identify the "the few vital CSFs" which represent 80 per cent of cumulative occurrence in the literature, these are:

1 The role of management leadership and quality policy

2 Supplier management

3 Process management

4 Customer focus

5 Training

6 Employee relations

7 Product

8 Quality data

9 Role of quality department

10 Human resource management and development

11 Design and conformance

12 Cross functional quality teams

13 Bench marking

14 Information and analysis

The other factors they described as the "useful many". There is no standard set for the success factors; every organisation, depending on its own internal and external environment will have its own set of factors. The primary success factor is to identify these factors and then capitalise on them.

\section{Research}

The aim of the study was to investigate the critical success factors in the effective implementation of self-assessment based on business excellence models in large government organisations; this 
Table 2 Targeted groups for the research and areas of investigation

\begin{tabular}{|c|c|c|}
\hline Investigation area & Target group & Method \\
\hline Perception of top management towards EFQM & Group A & Semi-structured interviews \\
\hline CSFs & $\begin{array}{l}\text { Group A } \\
\text { Group B }\end{array}$ & $\begin{array}{l}\text { Semi-structured interviews } \\
\text { Semi-structured interviews }\end{array}$ \\
\hline $\begin{array}{l}\text { knowledge level } \\
\text { awareness level } \\
\text { participation }\end{array}$ & $\begin{array}{l}\text { Group A } \\
\text { Group B } \\
\text { Group C }\end{array}$ & $\begin{array}{l}\text { Semi-structured interviews } \\
\text { Semi-structured interviews } \\
\text { Questionnaires }\end{array}$ \\
\hline $\begin{array}{l}\text { How to gain commitment towards the model } \\
\text { implementation }\end{array}$ & $\begin{array}{l}\text { Group A } \\
\text { Group B } \\
\text { Group C }\end{array}$ & $\begin{array}{l}\text { Semi-structured interviews } \\
\text { Semi-structured interviews } \\
\text { Questionnaires }\end{array}$ \\
\hline What prevents the implementation & $\begin{array}{l}\text { Group A } \\
\text { Group B } \\
\text { Group C }\end{array}$ & $\begin{array}{l}\text { Semi-structured interviews } \\
\text { Semi-structured interviews } \\
\text { Questionnaires }\end{array}$ \\
\hline \multicolumn{3}{|c|}{$\begin{array}{l}\text { Key: } \\
\text { Group A: Department Directors; } \\
\text { Group B: Heads of quality unit in every department } \\
\text { Group C: Employees including heads of sections, heads of units, engineers, technicians, accountants, clerks, etc. }\end{array}$} \\
\hline
\end{tabular}

was examined in the DM as a case study. A combination of qualitative and quantitative methodology was employed. Table 2 summarises the areas investigated, the target groups taking part, and the method used.

\section{Top Management Semi-Structured Interviews}

Extracting from the above table the department directors and quality specialists were interviewed to determine the most important CSFs and their ranking as seen by them. Their perception of the EM as a framework of TQM was also an aim of the interviews. Top managers' views on the best way to get commitment from their subordinates and the obstacles which prevent the optimal implementation and gain of the desired benefit were also aims of the interviews. Managers were encouraged to express any other issues they wanted to talk about. Open end questions were asked to encourage natural mode of expression (Cooper and Schindler, 1999).

A set of questions was asked to investigate, why they adopted the excellence model; what do they think about the effectiveness of the model; and what do they consider are the benefits from using it. The method used by van der Wiele et al (1996) was employed to know the main reasons for using the model as a base for self-assessment. The original list used by van der Wiele et al. (1996) was modified to suit the situation of the Municipality as a government organisation. Some reasons/motives were modified, namely, "pressure from head quarters" is changed to "pressure from top management" and "formal regulations from branch organisations" was deleted from the list since it is not applicable

\subsection{CSFs tailoring}

The 14 CSFs mentioned earlier was discussed with the top quality and strategy official in the municipality. The quality and strategy official was asked to check the list and add any factors believed to be 
Table 3 The comments of DM senior quality and strategy on the CSFs

\begin{tabular}{|c|l|l|}
\hline Rank & \multicolumn{1}{|c|}{$\begin{array}{c}\text { CSFs of Karuppusami and } \\
\text { Gandhinthan (2006) }\end{array}$} & \multicolumn{1}{|c|}{$\begin{array}{c}\text { Comment of the Senior Quality } \\
\text { Official in DM }\end{array}$} \\
\hline 1 & $\begin{array}{l}\text { The role of management leadership and } \\
\text { quality policy }\end{array}$ & $\begin{array}{l}\text { Separate the role of top management and leader- } \\
\text { ship from quality policy and add "Clear mission, } \\
\text { vision, values and objectives, understandable to } \\
\text { all employees" and rank it number two }\end{array}$ \\
\hline 2 & Supplier management & $\begin{array}{l}\text { Delete. Not applicable, for us supplier manage- } \\
\text { ment is one of the processes }\end{array}$ \\
\hline 3 & Process management & OK \\
\hline 4 & Customer focus & OK \\
\hline 5 & Training & $\begin{array}{l}\text { Merge. Part of the Human resource management } \\
\text { and development }\end{array}$ \\
\hline 6 & Employee relations & $\begin{array}{l}\text { Merge. Part of Human resource management and } \\
\text { development }\end{array}$ \\
\hline 7 & Product & $\begin{array}{l}\text { Delete. Not relevant for DM as a government organ- } \\
\text { isation. Process management covers the services }\end{array}$ \\
\hline 8 & Quality data & Merge. Included in Information and analysis \\
\hline 9 & Role of quality department & OK \\
\hline 10 & $\begin{array}{l}\text { Human resource management and de- } \\
\text { velopment }\end{array}$ & OK \\
\hline 11 & Design and conformance & $\begin{array}{l}\text { Delete. Not relevant for DM as a government or- } \\
\text { ganisation. Covered in Process management }\end{array}$ \\
\hline 12 & Cross functional quality teams & OK \\
\hline 13 & Bench marking & OK \\
\hline 14 & Information and analysis & OK \\
\hline & & \\
\hline
\end{tabular}

important and delete what is believed to be not important or not applicable in the particular case of the organisation, and also as a government organisation. Some of the CSFs were deleted from the list, others were merged. The comments of the quality director are summarised in Table 3.

A number of additional factors were also added. The DM exerts significant effort to spread knowledge about the strategy of the organisation to all the employees, hence the factor "clear mission, vision, values and objectives understandable by all employees" was added and considered to be second to "leadership" in importance. The director also added the following two factors at the bottom of the list, which were considered useful but not vital by Karuppusami and Gandhinthan (2006), these are:

1. Appreciation and reward

2. Work environment

After refining the list of CSFs, the quality and strategy official was asked to rank them in order of importance. This revealed the following set:

1. The role of management and leadership

2. Clear mission, vision, values and objectives, understandable to all employees 
3. Role of quality department

4. Human resource management and development

5. Process management

6. Customer focus

7. Cross functional quality teams

8. Information and analysis

9. Appreciation and reward

10. Bench marking

11. Work environment

The above list of CSFs was correlated with the original list of Karuppusami and Gandhinthan (2006) using spearman rank correlation. The factors that are not existing in either of the lists were marked with 0 (zero) rank in the other. The list (in a random order) was used as a basis for the interviews, and also in the questionnaires. Respondents were asked to rank them in order of importance to examine the correlation of views about the importance of the CSFs.

A total of twelve semi-structured interviews were conducted. An interesting preliminary observation was that five out of six directors accepted to have the interviews digitally reordered, while only one of the five quality specialists accepted. All interviews were done in Arabic language, but English language was frequently used during the interviews to confirm consensus and mutual understanding of terms used. The interviews were transcribed and translated to English. Similar answers of the interviewees were grouped under similar questions for ease of review, analysis and pattern matching. This technique is supported by Yin (2003).

To collect information from the employees a survey questionnaire was used. A total of 200 were distributed with 112 responses (response rate 56\%); from these 6 response sheets were disqualified and were not used in the database. Questionnaires were designed with two columns one in Arabic and the other in English language. Data was coded and entered in Excel spreadsheet for preliminary and simple analysis and then imported into SPSS V. 15.0 for windows for further analysis.

\subsection{General Information about the Implementation of DGEP}

In response to the question of who is responsible about leading the work with the DGEP in the department, responses were as follows:

Department Directors answers $(\mathrm{n}=6)$ :

all said the Department director is responsible

Quality Specialists ( $\mathrm{n}=5)$ :

3 said : the Department Director

2 said : the Head of Quality Unit

The respondents to interviews were asked about the way they manage the work with model and self-assessment, all confirmed that there is a team in the department, with the leadership of the department director and membership included the following personnel: 
- Heads of sections (in every department there are $2-4$ sections)

- Heads of units (in every section there are $2-4$ units)

- Head \& Staff of quality unit

- $\quad$ One or two Coordinators from each section (mainly responsible for evidence collection)

Three respondents referred to these teams as the: Strategic Transformation Team

The respondents were then asked about the way they prepare for self-assessment. All respondents confirmed that the process for preparation is a continuous process, where the criteria are divided between the team members and each member is responsible for building up evidence for each criteria. From the interviews and on reviewing of the documents, the technique followed for self assessment is a workshop technique, where the teams in every department prepare the required evidence for each criterion of the model. External assessors, with the coordination of the central quality department, evaluate the documents and score each criterion according to the RADAR logic. One respondent mentioned that they used electronic filing for saving criteria evidence.

As per the documents of the organisation, the self-assessment approach is summarised as:

1. Plan for assessment: an assessment scheduled is prepared in this stage and distributed to all departments. The assessment teams are formed and trained.

2. Conduct assessment and prepare plans: the teams in every department prepare the evidence for the model criteria for presentation to the assessors. The departments are assessed individually in assessment workshops by external assessors. Reports are prepared by the assessors' teams and are forwarded to the departments. Distinguished departments are honoured by the top management. It is the responsibility of each department to prepare the corrective action plans.

3. The central quality department does a follow up assessment.

Respondents were asked whether they conduct self-assessment other than the "compulsory" assessment by the central quality department. Their responses were as follows (total eleven respondents): two said yes; two said partially and all the rest said no stating "we don't have time" as the reason.

When asking about the corrective action plans, all respondent said that they prepare plans, 3 respondents mentioned that these plans are linked to the strategic and operational planning. 4 respondents mentioned that there are difficulties in the implementation of these plans due to:

1. High work load

2. Lack for communication between employees and leaders

3. Lack of coordination between different departments

4. The organisation is going through a strategic change

5. Too many uncoordinated quality and HR initiatives

\subsection{Perception About the DGEP}

The 'people perception' and their belief in the model as a general framework for future vision and as an integral part of the strategic planning process is necessary for the success of the model implementation. 
Table 4 Reasons for undertaking self assessment

\begin{tabular}{|c|l|r|c|}
\hline order & \multicolumn{1}{|c|}{ Item } & $\begin{array}{r}\text { Mean } \\
\text { Score }\end{array}$ & $\begin{array}{c}\text { Standard } \\
\text { Deviation }\end{array}$ \\
\hline 1 & To find opportunities for improvement & 4.36 & .674 \\
\hline 2 & To direct the improvement process & 4.36 & .809 \\
\hline 3 & To provide new motivation for the quality improvement process & 4.27 & .786 \\
\hline 4 & To manage the business & 4.00 & 1.000 \\
\hline 5 & To create a focus on the TQM model portrayed by the award criteria & 3.91 & 1.044 \\
\hline 6 & To go for a quality award & 3.91 & 1.446 \\
\hline 7 & To provide a benchmark against other organizations & 3.73 & 1.104 \\
\hline 8 & Formal regulations from government & 3.55 & 1.440 \\
\hline 9 & To help achieve quality system registration (e.g. IS0 9001) & 3.09 & 1.300 \\
\hline 10 & Pressure from top management & 3.00 & 1.414 \\
\hline 11 & Competitors were using self-assessment & 2.91 & .944 \\
\hline 12 & To strive for cost reduction & 2.82 & 1.168 \\
\hline 13 & Customers were demanding evidence of self-assessment & 2.73 & .905 \\
\hline 14 & Internal champion within the unit & 2.55 & 1.293 \\
\hline
\end{tabular}

Respondents were asked to indicate the importance of some of the reasons for conducting self-assessment using the DGEP model. The list of fourteen reasons or motives was adopted from van der Wiele et al (1996). Table 4 presents the findings, the reasons/motives are ranked from the most important (highest Mean=4.36) to the least important (lowest mean=2.55). The mean score method is used here as an indication of the importance of the statement.

The table shows that the top five reasons for using the model are mainly concerned with the internal interest of the organisation to find ways for improvement and represent the endeavour of the organisation towards TQM. "Formal regulations from government" has a mean of (3.55), which is above average, this is an indication of the "non-voluntary" reason for using the model. The factors from number 7 to 14 are related to external factors (van der Wiele et al.,1996). At the bottom of the list is the "internal champion within the unit" with a mean of (2.55), this indicates absence of such champions who promote the model.

\subsection{The Critical Success Factors}

The list of CSFs identified by Karuppusami and Gandhinthan (2006), was discussed with the top quality and strategy official in the Municipality where it was modified and ranked according to the importance to the Municipality. The new list was correlated with the original list using Spearman Rank Correlation. The correlation coefficient was found to be: $r_{s}=0.16$, comparing with the Spearman's Critical Values Table (Ramsey, 1989), we see that there is a difference in the view about the importance of CSFs.

Respondents to the interviews and surveys were asked to rank the list of eleven critical success factors (presented to them in a random order) as identified by the top quality official. Figure 3 represents the results: 


\section{Fig. 3 Spearman rank correlation}

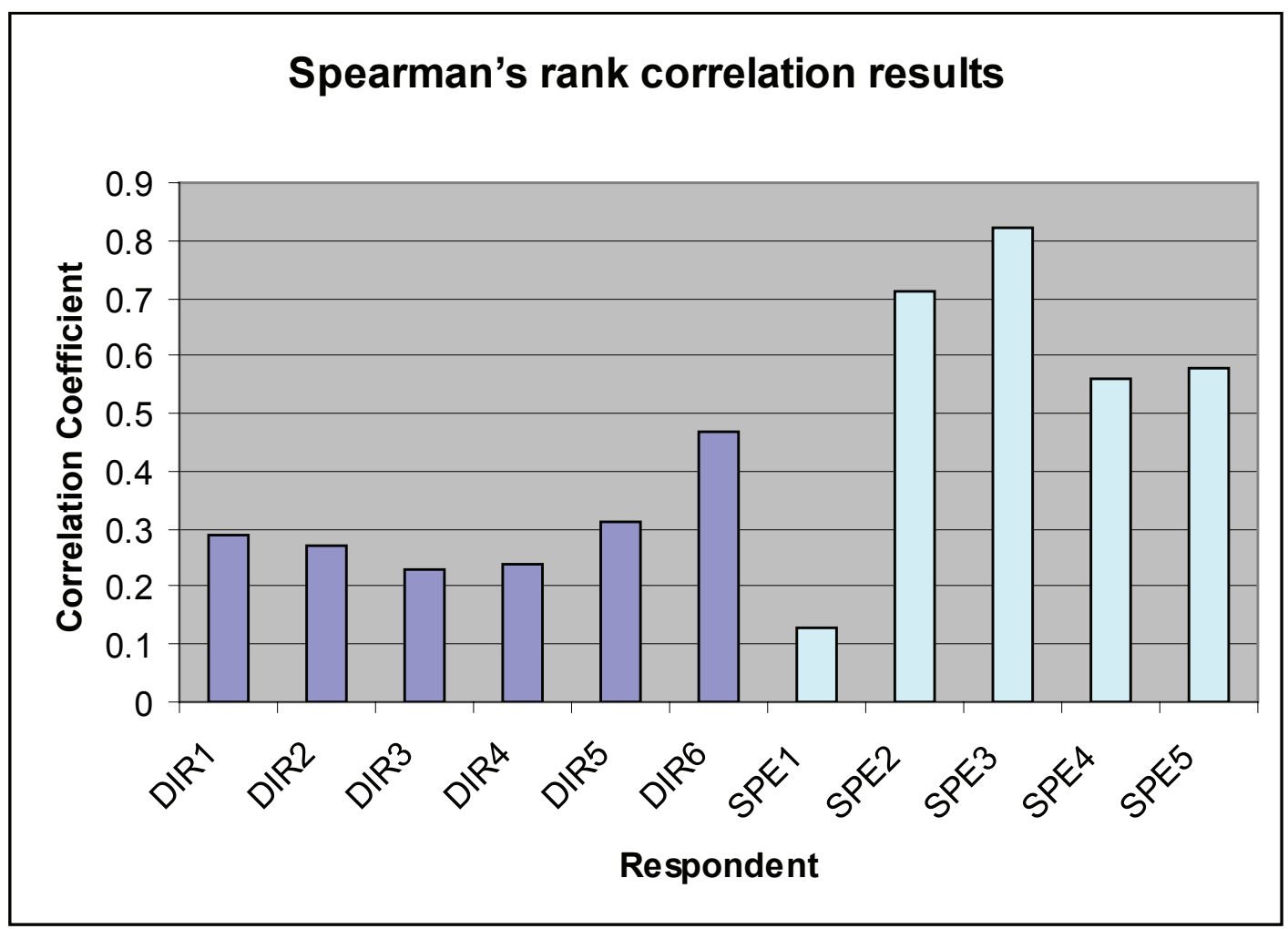

Looking at the Spearman's Critical Values Table (Ramsey, 1989), the Correlation coefficients for the number of pairs $=11(\mathrm{~N}=11), r_{s}=$

$$
\begin{aligned}
& 0.618 \text { with level of significance }=0.05 \\
& 0.708 \text { with level of significance }=0.02 \\
& 0.755 \text { with level of significance }=0.01
\end{aligned}
$$

And looking at the research results, we can say:

1. There is significant difference between the view of Karuppusami and Gandhinthan findings and the Municipality senior quality official.

2. The Highest correlation coefficient in the group of directors is 0.47 (significance less between $(0.2$ to 0.1$)$, which indicates diference in the views with the senior quality officer.

3. In the group of quality specialist 2 out of 5 have a coefficient higher than 0.618 , and 3 specialists have a lower coefficient.

4. Quality specialists have better correlation compared with that of the department directors. There is a difference in the views of the Senior officer and that of Directors and quality specialists, and the difference is higher with the directors.

Similarly the CSFs list was given to respondents to the questionnaires to rank; people who answered that they have no knowledge about DGEP were excluded from the sample in this test. $34.7 \%$ of the employees $(n=72)$ have negative rank correlation $\left(r_{s}<0\right)$, and $95.8 \%$ have no sig- 
nificant correlation $\left(r_{s}<0.618\right)$, that means only $4.2 \%$ have a significantly positive rank correlation $(r>0.618)$, with the senior quality official.

\section{Findings and Discussion}

Dubai Municipality has about ten years of experience with the implementation of the DGEP business excellence model and a long heritage in the use of different TQM tools and techniques. This research tried to study the experience of DM in the implementation of the excellence model (DGEP). Huge amount of data was collected and analysed using different techniques.

From the analysis of interviews it was clear that all directors confirm their responsibility on leading the process of the model implementation and they all confirm their direct involvement, except one who argued that, his involvement is necessary at the strategic level only, and he suggested that giving the quality teams more autonomy on the way they want to implement the model will enhance their ownership and give them more enthusiasm for work and hence better outcomes. On the other hand two out of five quality specialists said that the responsibility is actually shouldered to the heads of quality units in the departments, nevertheless, all directors and specialists confirm the importance of top management commitment and involvement in the process.

From all the responses of the interviews it was clear that in every department there is a team responsible for quality and strategy issues, these teams are always led by the department directors with the membership of the head of sections, heads of quality units, and one or two representatives from each section to act as coordinators in their sections.

There was consensus among the respondents that the process of preparation for self-assessment is a continuous and an ongoing process, and there was a strong emphasis on the evidence collection and filing process for self-assessment. The general trend in all departments investigated was that the model criteria were divided between different people, in other words there are criterion owners in the departments and their responsibility is mainly evidence collection.

The leaders of the organisation agree that the model is comprehensive and covers all the aspects related to the organisation. This is important and is a predictor of commitment. Although all interviewees agreed on the positive effect of the model on performance, that effect was less than medium ( mean $=2.89$ in a five point scale), also there is a varying opinion on the degree of improvement due to the use of the model; some departments indicate high contribution while other did not. This indicates a non uniform deployment between departments and is an indication of the need for knowledge sharing and cross-functional teams. Those who mentioned little contribution of the model in performance improvement referred to high work load as a primary reason, followed by time and effort required to use the model and the assessment process itself. The EFQM (2003) stresses the fact that the organisation must choose the assessment approach that best suits its business and the reason for conducting the assessment.

A unified purpose is an important factor in the success of any team or organisation. Looking at the correlation of priorities of the eleven critical success factors discussed, there appears to be a fairy significant difference between the senor management in their views. Recalling the organisation's structure, it is clear that there is a diverse focus and large difference in the job descriptions between the functional departments. Every department has a different set of factors that 
are considered important for them. The authors recommend further investigation of this issue, so that people can agree on a common purpose. To align the organisation to a common purpose also needs an understanding of each department's business and requirements. Meeting with the department and agreeing on a set of criteria that help them improve their performance will provide more harmony and synchronisation in the overall performance.

\subsection{Working with the model}

Benefits gained from the practice of self-assessment were identified. The research showed that the achievement of the perceived benefits was not satisfactory; most of the responses were between "little improvement" to "medium improvement". It is worth considering the reasons for not succeeding, as stated by the respondents:

1. the model is difficult

2. it needs long time and big effort

3. focus on score rather than improvement

These results suggest a need to focus on the benefits from the process. The results showed understanding of the theory and importance of the model, a further program could focus on the benefits. The authors also recommend that a document be produced by the organisation explaining the model in a simple language, that all people from different specialisations can understand.

Most of the difficulties identified from the research are related to the model and the way it is implemented. People in the organisation face difficulties with the preparation of evidence files for the purpose of the assessment workshop, and the assessment technique itself (workshop) was found to be a big inhibitor of successful implementation. People also found the model difficult to understand by every one. There is a need for better communication due to the huge size of the organisation and coordination between different departments. The authors recommend a different assessment technique to address these issues.

\subsection{Lessons learned from the study}

1 Adopting a framework for TQM, such as the EM or DGEP, for organisational self assessment contributes to the success of the organisation, provided that it is used for continuous improvement rather that winning quality awards

2 Top management commitment and involvement in in TQM initiatives is a key success factor

3 It is important to align the views and expectations of top management about the excellence model implementation with those of the quality specialists in the organisation

4 The assessment technique used should match the organisation's size, maturity and purpose for assessment.

\section{References}

Al-Mary, K. , Ahmed, A.M. and Zairi,M., (2007), "Excellence in service: an empirical study of the UAE banking sector”, International Journal of Quality Management, Vol. 24, No. 2, pp. 164-176 
Badri, M., Davis, D. and Davis D (1995). 'Astudy of measuring the critical factors of quality management', International Journal of Quality \& Reliability Management, Vol. 12, No. 2, pp. 36-53

Cooper, D.R. and Schindler, P.S., (1998), Business Research Methods, Tata McGraw-Hill Publishing Company Ltd. New Delhi

Dale, B.G., (1996). "Benchmarking on total quality management adoption: a position model', Benchmarking for Quality Management \& Technology, Vol. 3, No. 1, pp.28-37

DGEP, (2007). Dubai Government Excellence Programme, Dubai, UAE

Dubai Municipality (2007) "Dubai Municipality Profile”, http://www.dm.gov.ae/DMEGOV/dm-mp-aboutus

European Foundation for Quality Manageme (2003). EFQM Excellence Model, EFQM, Brussels

European Foundation for Quality Manageme (2003). Assessing for Excellencel, EFQM, Brussels

Fernandes, C. and Awamleh, R. (2006) "Impact of organisational justice in an expatriate work environment" Management Research News, Vol. 29 No. 11, pp. 701-712

Karuppusami, G. and Gandhinathan, R. (2006). 'Pareto analysis of critical success factors of total quality management A literature review and analysis', The TQM Magazine, Vol. 18 No. 4, pp. 372-385

Ramsey, P.H., (1989), “Critical Values for Spearman's Rank Order Correlation”, Journal of Educational Statistics, Vol. 14, No. 3, pp. 245-253

Samuelsson, P. and Nilsson, L.E. (2002). 'Self-assessment practice in large organizations, experience from using the EFQM excellence model', International Journal of Quality \& Reliability Management, Vol. 19, No. 1, pp. $10-23$

van der Wiele, A., Williams, A.R.T., Dale, B.G., Carter , G., Kolb , F., Luzon , D.M., Schmidt , A. and Wallace, M. (1996). 'Self-assessment A study of progress in Europe's leading organizations in quality management practices', International Journal of Quality \& Reliability Management, Vol. 13 No. 1, pp. 84-104,

Yin, R.K. (2003), Case Study Research Design and Methods, Sage Publications, Thousand Oaks, CA, 